\title{
Public Transport Knowledge Management in Local Communities
}

\author{
Pratya Nuankaew $^{(1), *}$, Kanakarn Phanniphong ${ }^{(2)}$, Patchara Nasa-ngium ${ }^{(3)}$, Wongpanya \\ Nuankaew ${ }^{(4)}$ \\ ${ }^{(1)}$ School of Information and Communication Technology, University of Phayao, Phayao, 56000, \\ Thailand \\ ${ }^{(2)}$ Faculty of Business Administration and Information Technology, Rajamangala University of \\ Technology Tawan-Ok, Bangkok, 10400, Thailand \\ ${ }^{(3)}$ Faculty of Science and Technology, Rajabhat Maha Sarakham University, Maha Sarakham, 44000, \\ Thailand \\ ${ }^{(4)}$ Faculty of Information Technology, Rajabhat Maha Sarakham University, Maha Sarakham, 44000, \\ Thailand \\ ("Corresponding author's e-mail: pratya.nu@up.ac.th)
}

Article History: Received: 10 November 2020; Revised 12 January 2021 Accepted: 27 January

2021; Published online: 5 April 2021

\begin{abstract}
The purpose of this research is to construct an application prototype from the study of public transport problems in the local communities of Thailand. There are three main goals for research to be successful: (1) To study problems and situations in which communities are affected by public transport. (2) To design and standardize the management of problems and situations in which the community is affected by public transport. (3) To construct a public transport application prototype for local communities of Thailand. Population and sampling were scoped from the public transport service provider in Phayao Province, Thailand. The prototype was constructed with an Android Mobile Application. The results of the study showed that the developed application prototypes showed a high level of satisfaction (total means is equal to 3.95 , S.D. is equal to 0.73) with the design and implementation of the prototype. In the future, the researcher will bring the application to the test and deployment.
\end{abstract}

Keywords: Knowledge Management, Local Public Transport, Thailand Local Communities, Learning Analytics

\section{Introduction}

The University of Phayao has grown rapidly over the past two decades. The exponential growth of the University of Phayao has resulted in an increasing number of students and interested people joining the university every year. It has resulted in a growing demand for public transport to travel between the University of Phayao and students.

The University of Phayao currently consists of 20 academic departments that provide education at the basic education level, undergraduate level, and graduate level. It consists of six groups: The 1st group is the Humanities and Social Sciences, including School of Law, School of Business and Communication Art, School of Liberal Arts, School of Political and Social Science, and School of Education. The 2nd group is the Science and Technology, including School of Agriculture and Natural Resources, School of Science, School of Engineering, School of Architecture and Fine Arts, School of Information and Communication Technology, and School of Energy and Environment. The 3rd group is the Health Sciences, including School of Medical, School of Nurse, School of Dentist, School of Medical Science, and School of Allied Health Sciences. The 4th group is the Graduate School. The 5th group is the Demonstration School. The 6th group is University of Phayao Hospital School of Medicine.

The research conducted on the number of students in the University of Phayao shows the relevance of the number of students increasing every year (Nuankaew et al., 2020). At the same time, the number of studies, research, and development of technology to be applied for the benefit of the community is not reasonable. However, the Business Computer Program at the School of Information and Communication Technology, the University of Phayao offers students the opportunity to undertake senior programs. It is a project-based education management principle that helps students reach critical issues in the area of the University of Phayao.

The area and scope of the research that the research team has identified are issues related to public transport management. There are three main objectives; the 1st objective is to study problems and situations in which 
communities are affected by public transport. The 2 nd objective is to design and standardize the management of problems and situations in which the community is affected by public transport. Finally, the 3rd objective is to construct a public transport application prototype for local communities of Thailand.

The instruments and population used in the research included interviews to study the problems affected by public transport, Android application development tools, and a questionnaire to assess satisfaction with the application. The samples selected to be used in the research were divided into three areas: the 1st area is 9 lecturers in the Business Computer Program, the 2nd area is 17 public transportation service providers in the local community at the University of Phayao, and the 3rd area is 34 application testers.

The expected outcome is a prototype application for supporting and providing public transportation for the local communities in the University of Phayao area. The researcher has high expectations that the application will be a useful tool for the community in the future.

The details of the research presentation are divided into five main sections: the 1st section is explaining the stage of the arts of the research, the 2nd section is summarizing the literature reviews and related research, the 3rd section is the presentation of the research methodology, the 4th section presents the results of the research, and the 5 th section is the overview of the research results.

\section{Material and Methods}

The research conducted on the number of students in the University of Phayao shows the relevance of the number of students increasing every year (Nuankaew, 2020; Nuankaew et al., 2020; Phanniphong et al., 2018). At the same time, the number of studies, research, and development of technology to be applied for the benefit of the community is not reasonable. However, the Business Computer Program at the School of Information and Communication Technology, the University of Phayao offers students the opportunity to undertake senior programs. It is a project-based education management principle that helps students reach critical issues in the area of the University of Phayao.

The area and scope of the research that the research team has identified are issues related to public transport management. There are three main objectives; the 1st objective is to study problems and situations in which communities are affected by public transport. The 2 nd objective is to design and standardize the management of problems and situations in which the community is affected by public transport. Finally, the 3rd objective is to construct a public transport application prototype for local communities of Thailand.

The instruments and population used in the research included interviews to study the problems affected by public transport, Android application development tools, and a questionnaire to assess satisfaction with the application. The samples selected to be used in the research were divided into three areas: the 1st area is 9 lecturers in the Business Computer Program, the 2nd area is 17 public transportation service providers in the local community at the University of Phayao, and the 3rd area is 34 application testers.

The expected outcome is a prototype application for supporting and providing public transportation for the local communities in the University of Phayao area. The researcher has high expectations that the application will be a useful tool for the community in the future.

The details of the research presentation are divided into five main sections: the 1st section is explaining the stage of the arts of the research, the 2nd section is summarizing the literature reviews and related research, the 3rd section is the presentation of the research methodology, the 4th section presents the results of the research, and the 5th section is the overview of the research results.

The research methodology was carried out according to Software Development Life Cycle (SDLC) principles by selecting the V-Model quality assurance method as an effective method for software development. The V-Model components consist of 7 key phases: the 1st phase is the define requirements phase, the 2nd phase is the system architecture phase, the 3rd phase is the detailed design phase, the 4th phase is the development phase, the 5th phase is the build and test phase, the 6th phase is the system integration and test phase, and the last phase is the deployment and verification phase (Forsberg \& Mooz, 1991).

The importance and relationships of each phase are clearly assessed at every stage, as shown in the Figure 1. 


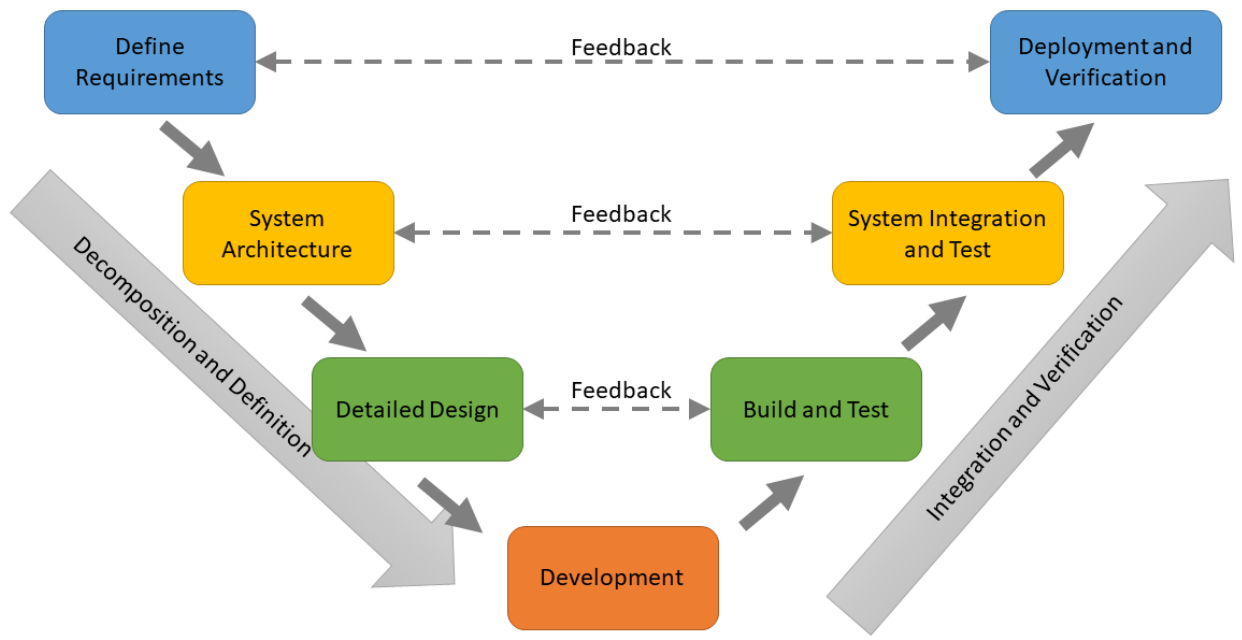

Figure 1. V-Model Quality Assurance Method (Forsberg \& Mooz, 1991; Ruparelia, 2010)

The v-model or "Vee-Model" was presented in NASA research as a part of the Software Management and Assurance Program, known as SMAP (Forsberg \& Mooz, 1991). The v-model principle is an approach that has been developed following the Waterfall model. It uses the concept of an upside-down bipolar assessment for all phases of evaluation, known as V-sharp. The details of the V-Model and its application in research are presented in the following subsections.

\subsection{Define Requirements Phase}

The define requirements phase is aimed to understand user requirements, develop system concepts, and validation schemes (Forsberg \& Mooz, 1991). This research has hypothesized about the problems that arise in the community. Researchers have discovered that the community needs to bring technology to support solving public transport problems.

\subsection{System Architecture Phase}

The system architecture phase is intended to describe the performance requirements in the system that are required and developed (Forsberg \& Mooz, 1991). This research studies the problems of the community. The researcher plans to study the problems related to people who are related to the University of Phayao and the community.

\subsection{Detailed Design Phase}

The detailed design phase is aimed at specification into building the document and inspection plans (Forsberg \& Mooz, 1991). This prototype application has two sub-objectives. The 1st sub-objective is to encourage Business Computer students to develop projects to develop learners' knowledge. The 2nd subobjective is to create technology to provide academic service to the community.

\subsection{Deployment Phase}

The deployment phase focuses on the assembly of code and technology in developing the system for its intended purpose (Forsberg \& Mooz, 1991). Appropriate technologies for community and public transport in Thailand is now using mobile technology to support. Researchers choose to use Android technology (Calimag et al., 2014; Liang \& ZHANG, 2009) to develop application prototype. 


\subsection{Build and Test Phase}

The build and test phase are to verify from the document (Forsberg \& Mooz, 1991). At this stage, the researchers are set in the learning process management in the Business Computer program at the School of Information and Communication Technology, the University of Phayao. This process consists of three phases: the first phase is the proposed research topic, the second phase is the investigation of the progress of the research, and the third phase is to present the research findings.

\subsection{System Integration and Test Phase}

The system integration and test phase are aimed to integrate the system and perform system verification to performance specifications (Forsberg \& Mooz, 1991). In this section, the researcher coordinated with the public transportation service providers to evaluate the design and implementation of the prototype program.

\subsection{Deployment and Verification Phase}

The deployment and verification phase are intended to find the conclusion and acceptance of the system (Forsberg \& Mooz, 1991). In this research, the researchers chose a questionnaire to assess the satisfaction of the developed prototype system.

\section{Results and Discussion}

The finding and discussion of the research are followed the research objectives as three main areas: (1) Findings from the current situation, (2) Design results and prototype development, and (3) Results of the prototype satisfaction assessment.

\subsection{Critical Points of Public Transport in Local Communities}

The findings of the research, the researchers discovered that there are many significant issues. A prime example is the inability to properly schedule public transport services due to lack of user and operator information. In addition, the service provider is unable to plan the service for each period of time, while the user does not know how to contact the provider.

The conclusion from the survey revealed that the service provider and the user needed a system that could be matched between the two parties. The researchers have therefore designed a system that can serve both parties, consisting of five systems, which are detailed in the following sections.

\subsection{Prototype of Public Transport Application}

The prototype application has been designed and developed in accordance with the flow chart diagram as shown in Figure 2. It consists of five systems: reservation system, membership system, complaint system, service provider system, and user system. Details and developed prototypes are presented in the following subsections. 


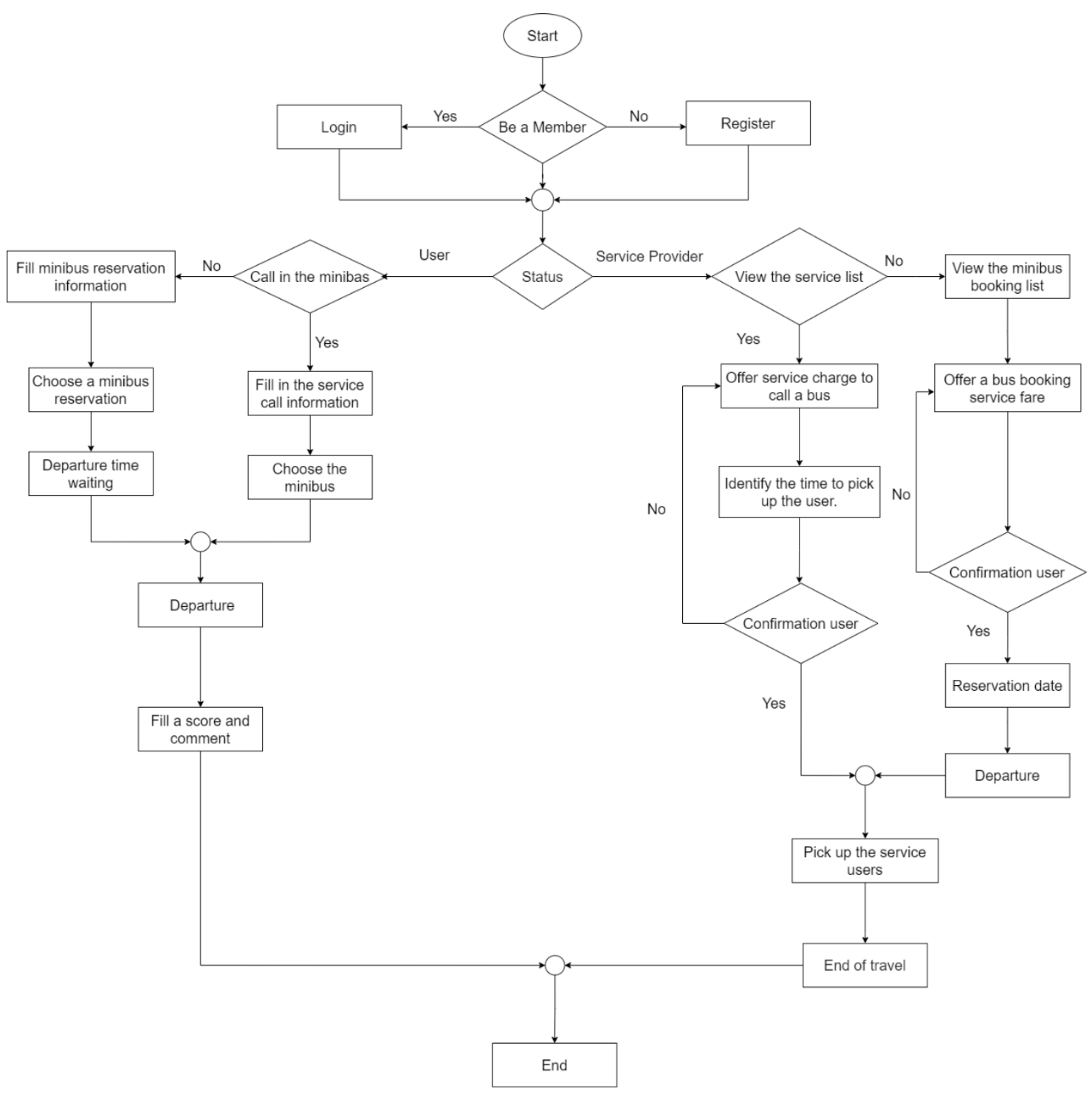

Figure 2. Flow Chart of Prototype Application

\subsection{Membership System}

The interfaces of the membership system are presented in Figure 3 to Figure 6. 


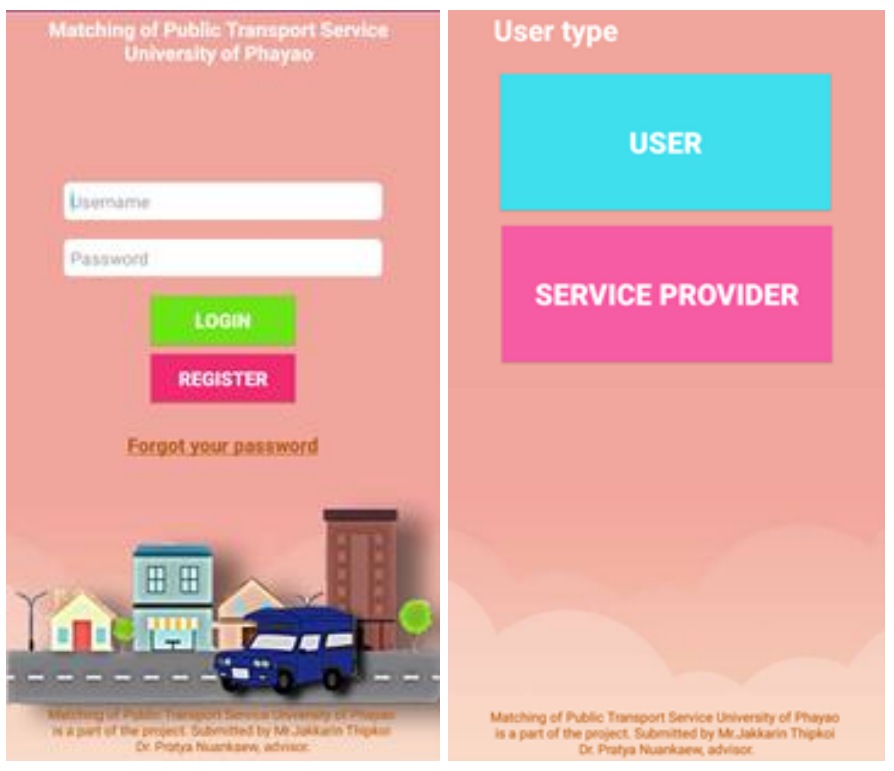

Figure 3. Interface of the Membership System
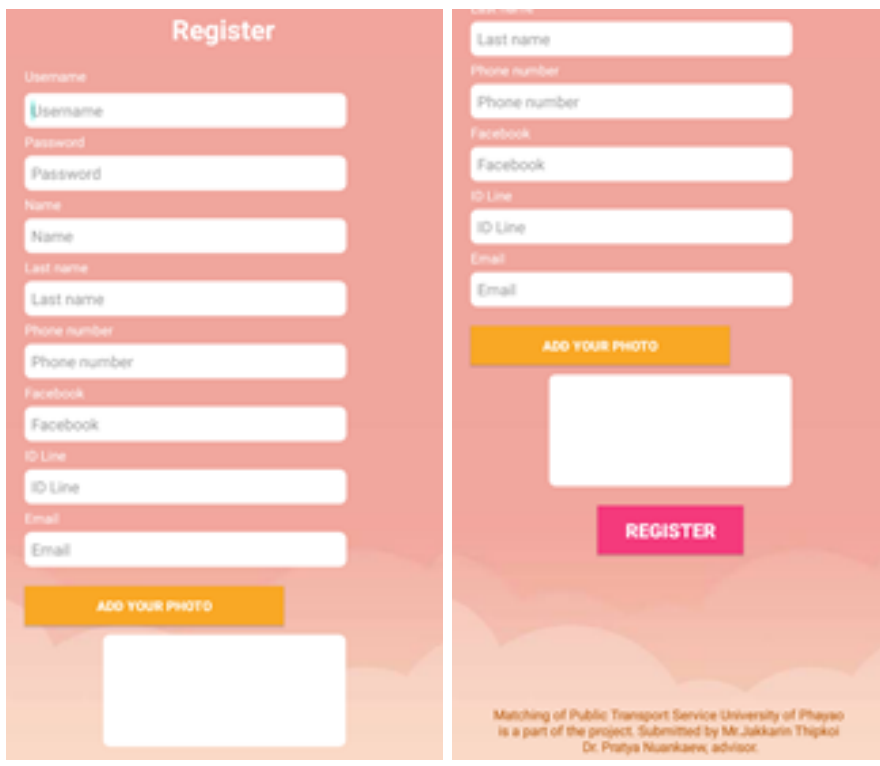

Figure 4. Interface of Register for Users 


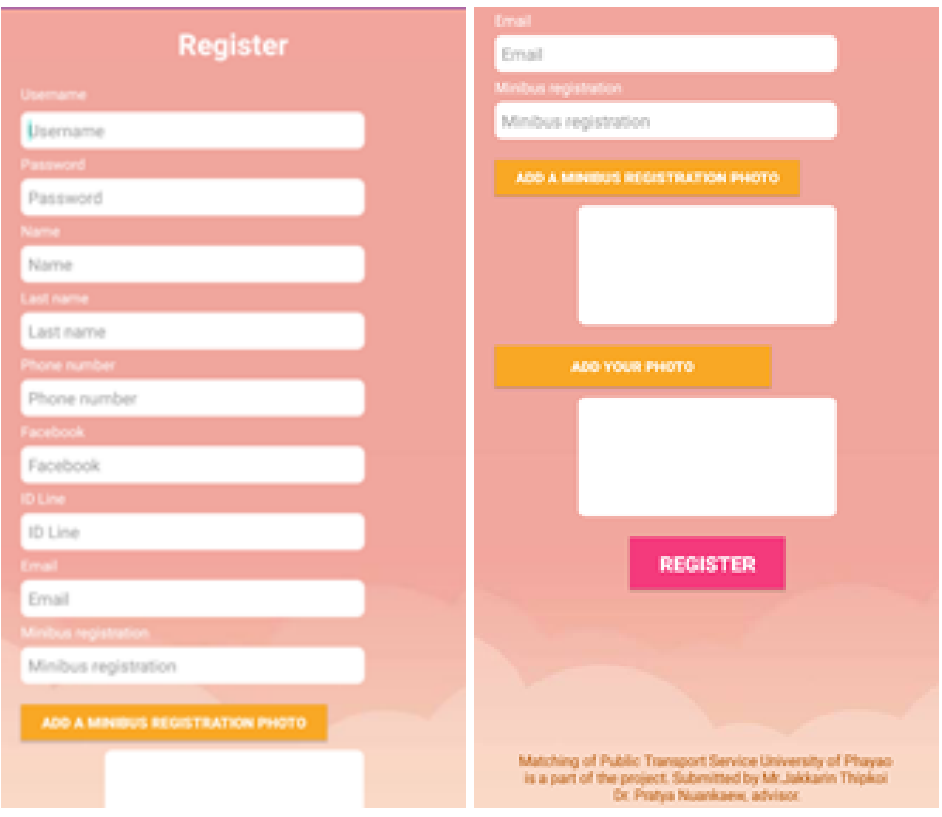

Figure 5. Interface of Register for Service Provider

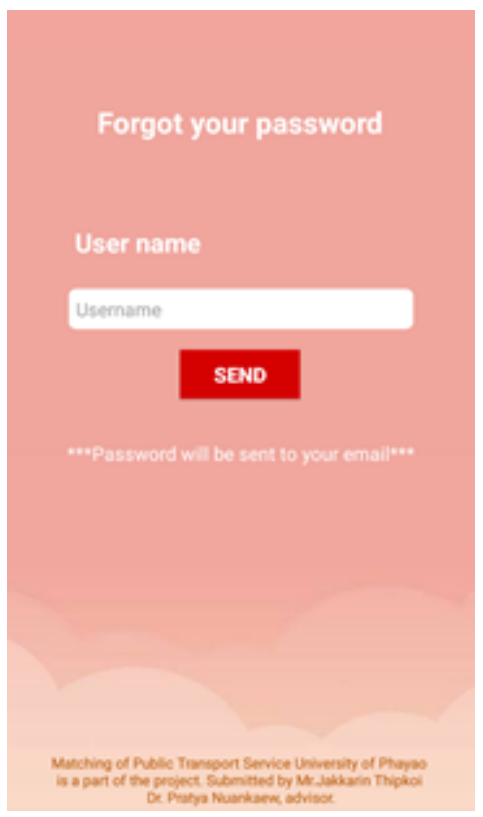

Figure 6. Interface of the Membership System

\subsection{Service System}

The interfaces of the service system are presented in Figure 7 to Figure 14. 


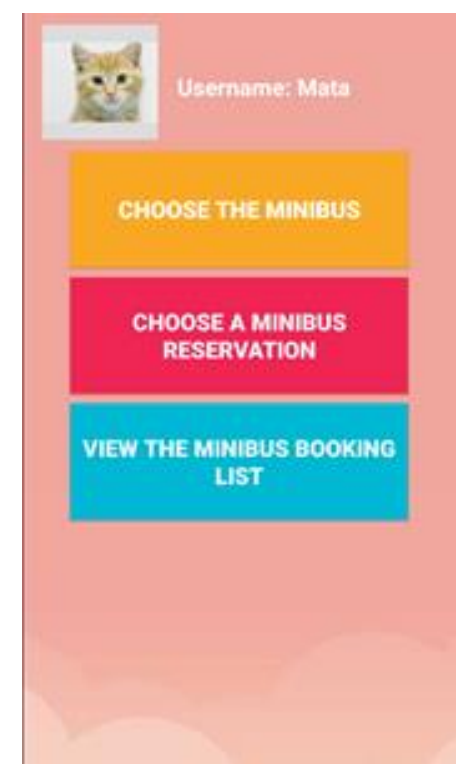

Figure 7. Interface of the Service Provider System

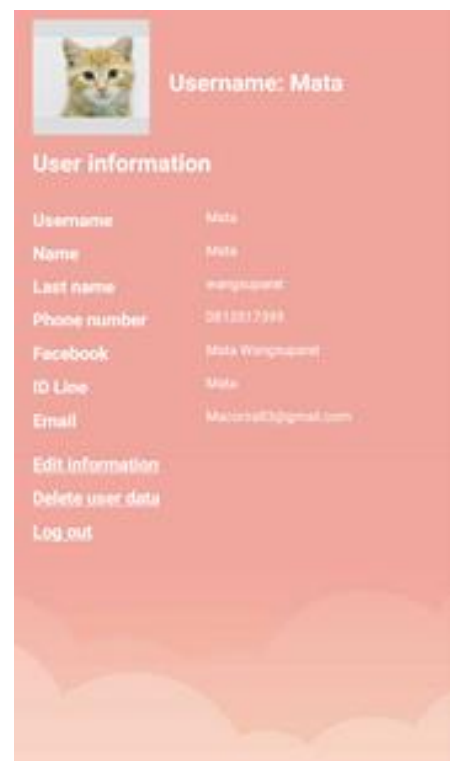

Figure 8. Interface of the User Information 


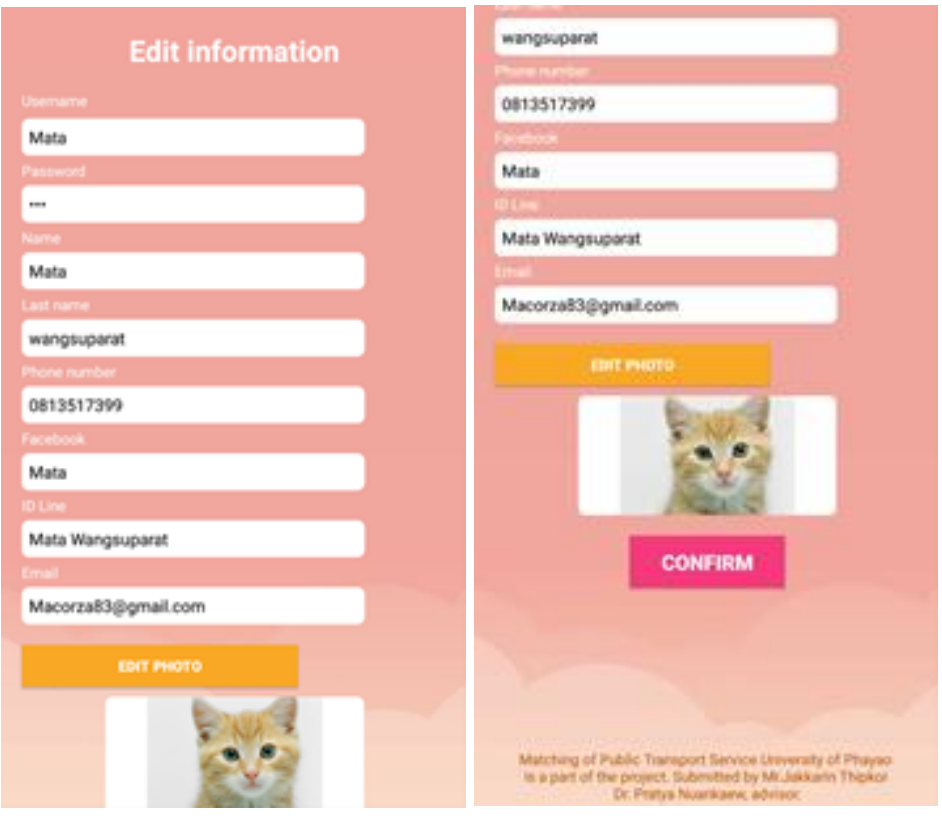

Figure 9. Interface of Editing User Information

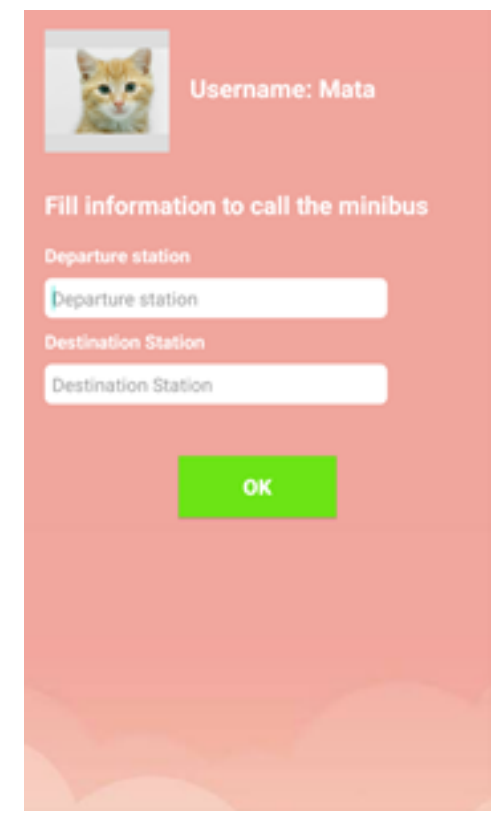

Figure 10. Interface of the Service Provider System 


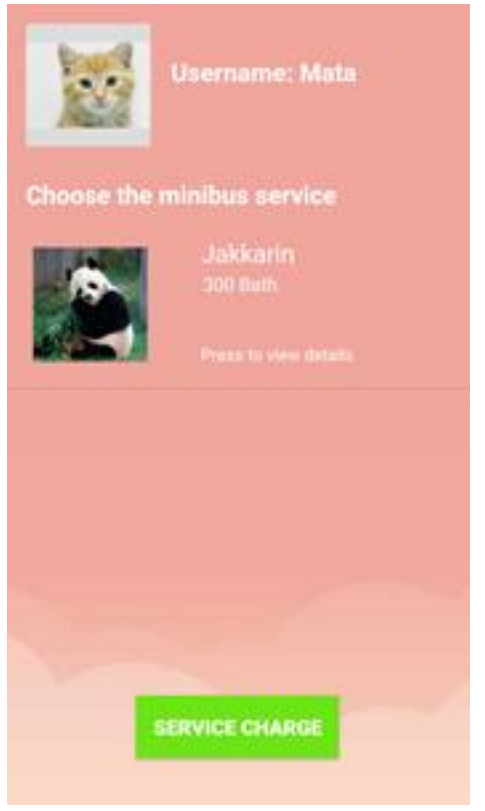

Figure 11. Interface of the Service Provider System

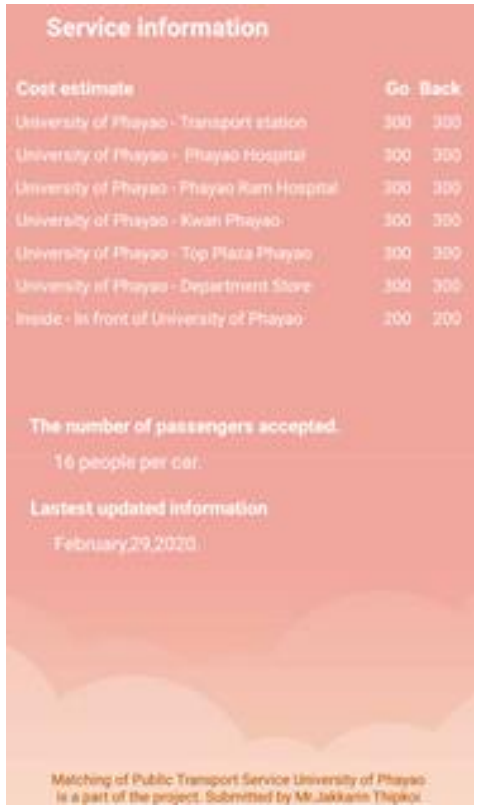

Figure 12. Interface of the Service Provider System 


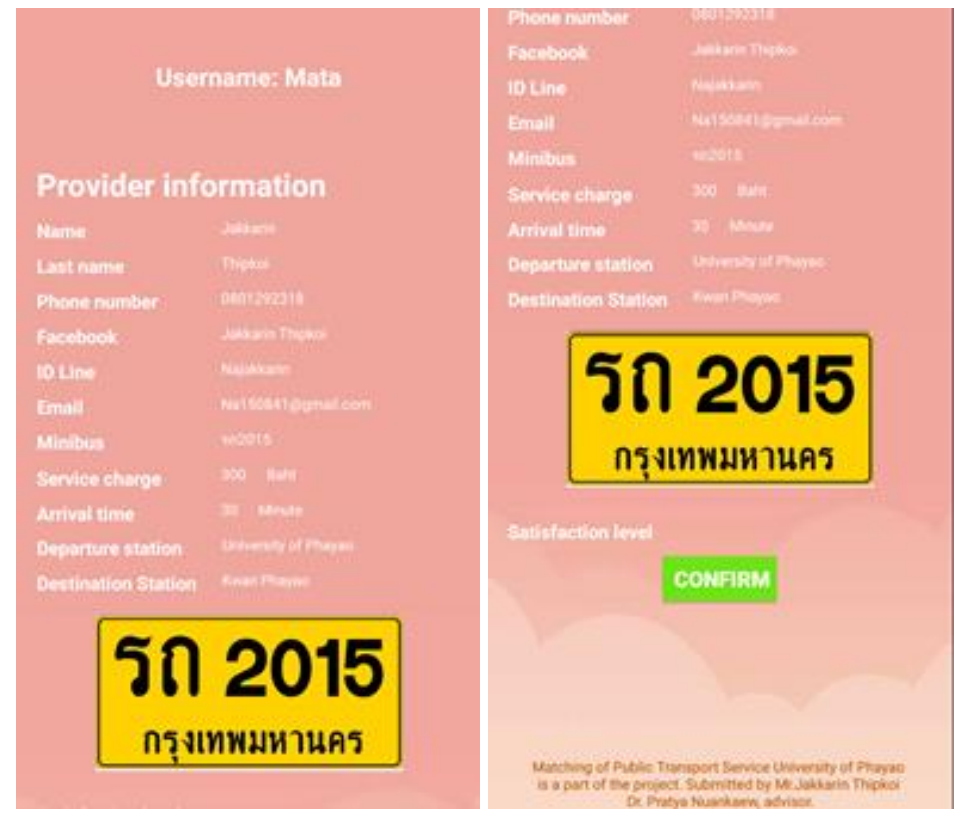

Figure 13. Interface of the Confirm Booking

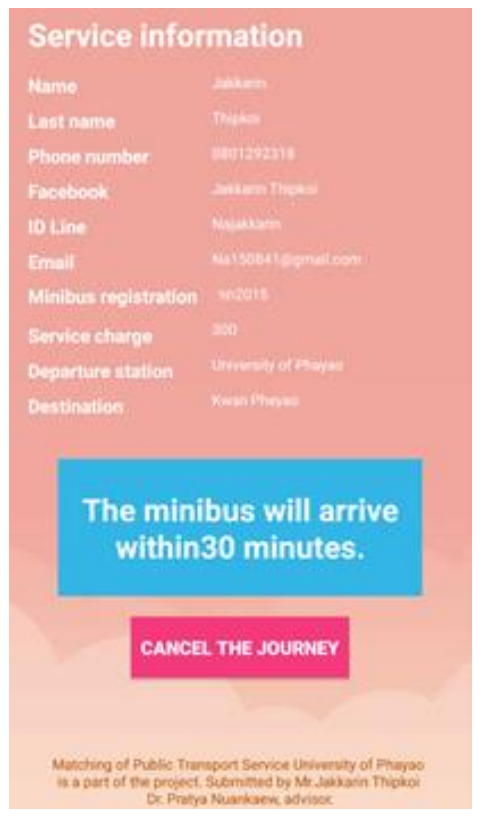

Figure 14. Interface of the Service Provider System

\subsection{Reservation System}

The interfaces of the reservation system are presented in Figure 15 to Figure 16. 


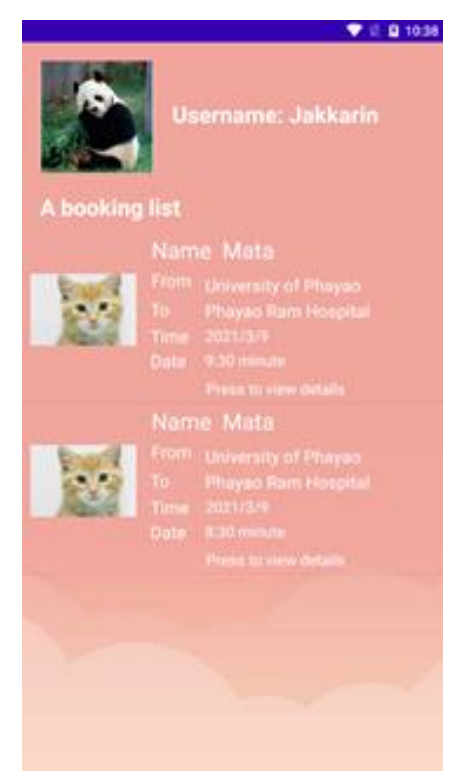

Figure 15. Interface of the User System

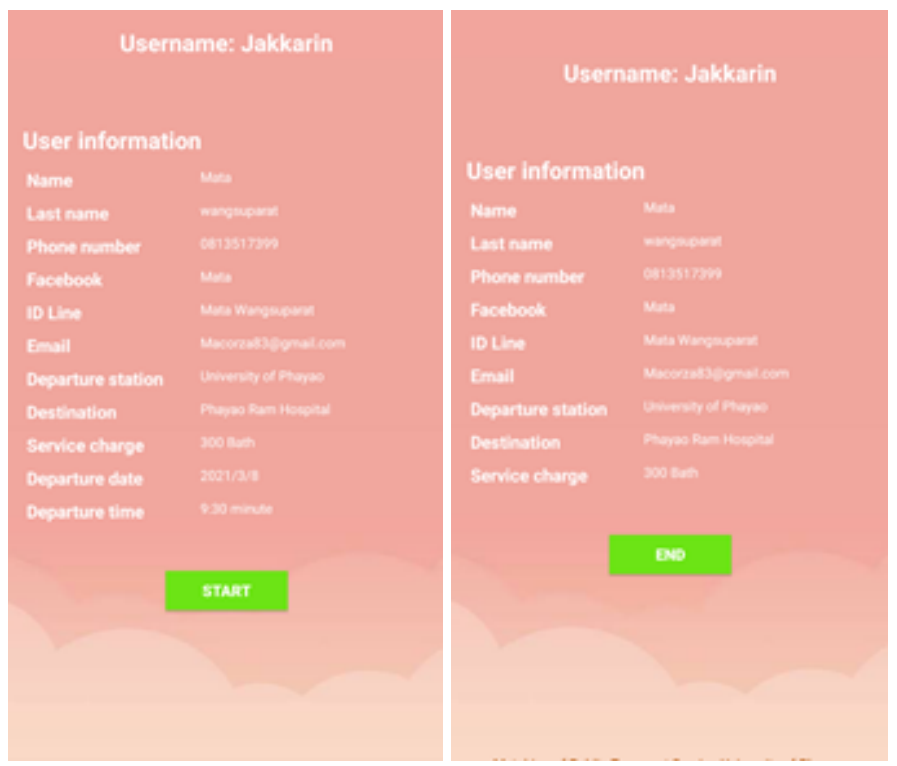

Figure 16. Interface of the User System

\subsection{Complaint System}

The interfaces of the membership system are presented in Figure 17. 


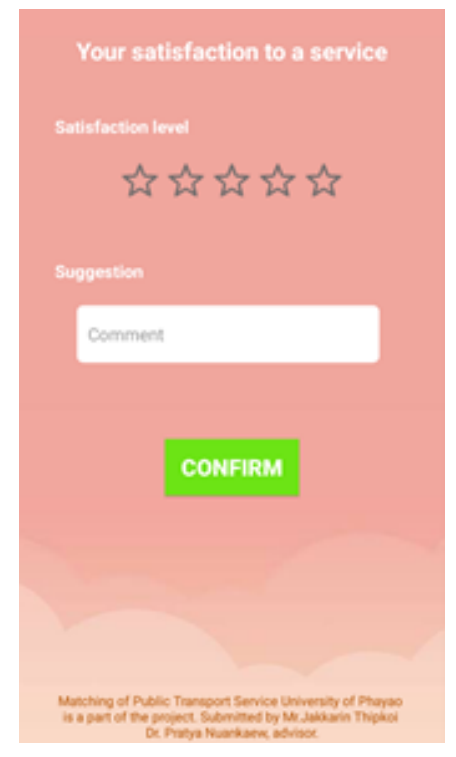

Figure 17. Interface of the Complaint System

\subsection{Satisfaction toward the Prototype}

Respondents consisted of 60 items from 3 groups: 9 instructor, 17 service providers, and 34 application testers. There are four main stages in questionnaire: the 1st stage is about the functional ability of the application. The 2nd stage is about the usability of the application. The 3rd stage is about the performance of the application. Finally, the last stage is about the security of the application. All stages and details of the questionnaire are shown in Table 1.

Table 1: Questions on the Questionnaire

\begin{tabular}{|c|c|}
\hline Stage & Topics and Questions \\
\hline \multicolumn{2}{|c|}{ Stage 1: Functional Ability of the Application } \\
\hline Stage 1.1 & Accuracy of the system access \\
\hline Stage 1.2 & Function to access the system \\
\hline Stage 1.3 & Accuracy of entering and editing data \\
\hline \multicolumn{2}{|c|}{ Stage 2: Usability of the Application } \\
\hline Stage 2.1 & Suitability of the character \\
\hline Stage 2.2 & Suitability of the button and placement \\
\hline Stage 2.3 & Suitability of the text and sentence \\
\hline Stage 2.4 & Suitability of the interface \\
\hline \multicolumn{2}{|c|}{ Stage 3: Performance of the Application } \\
\hline Stage 3.1 & Response of the application \\
\hline Stage 3.2 & Suitability to transmit information \\
\hline Stage 3.3 & Accuracy of the data and computing \\
\hline Stage 3.4 & Accuracy of matching providers and users \\
\hline \multicolumn{2}{|c|}{ Stage 4: Security of the Application } \\
\hline Stage 4.1 & Suitability of the permission \\
\hline Stage 4.2 & Suitability of the login \\
\hline Stage 4.3 & Suitability of data protection \\
\hline
\end{tabular}

Table 1 shows details and related questions. Where analysis results and summaries from respondents are shown in Table 2. 
Table 2: Data Analysis

\begin{tabular}{|c|c|c|c|}
\hline Stage & Mean & S.D. & Interpretation \\
\hline \multicolumn{4}{|c|}{ Stage 1: Functional Ability of the Application } \\
\hline Stage 1.1 & 3.95 & 0.79 & Accepted \\
\hline Stage 1.2 & 3.93 & 0.80 & Accepted \\
\hline Stage 1.3 & 3.97 & 0.71 & Accepted \\
\hline Average & 3.95 & 0.76 & Accepted \\
\hline \multicolumn{4}{|c|}{ Stage 2: Usability of the Application } \\
\hline Stage 2.1 & 3.93 & 0.66 & Accepted \\
\hline Stage 2.2 & 3.80 & 0.78 & Accepted \\
\hline Stage 2.3 & 3.95 & 0.70 & Accepted \\
\hline Stage 2.4 & 3.85 & 0.66 & Accepted \\
\hline Average & 3.88 & 0.70 & Accepted \\
\hline \multicolumn{4}{|c|}{ Stage 3: Performance of the Application } \\
\hline Stage 3.1 & 4.02 & 0.75 & Accepted \\
\hline Stage 3.2 & 3.95 & 0.75 & Accepted \\
\hline Stage 3.3 & 4.07 & 0.71 & Accepted \\
\hline Stage 3.4 & 4.07 & 0.66 & Accepted \\
\hline Average & 4.03 & 0.71 & Accepted \\
\hline \multicolumn{4}{|c|}{ Stage 4: Security of the Application } \\
\hline Stage 4.1 & 3.85 & 0.76 & Accepted \\
\hline Stage 4.2 & 3.92 & 0.70 & Accepted \\
\hline Stage 4.3 & 4.00 & 0.82 & Accepted \\
\hline Average & 3.92 & 0.76 & Accepted \\
\hline Total Average & 3.95 & 0.73 & Accepted \\
\hline
\end{tabular}

Table 2 shows the results of the analysis of the level of satisfaction with the developed prototype application. From the analysis, the total average is equal to 3.95 (S.D. equal to 0.73 ). It can be interpreted as having a high level of acceptance. In each of the questions asked, there also was a high level of satisfaction. From all three areas of the research objective, it was discovered that this research was very successful that stakeholders should support in the future.

\section{Conclusions}

This research is aimed to construct an application prototype from the study of public transport problems in local communities of Thailand. There are three main goals for research to be successful: (1) To study problems and situations in which communities are affected by public transport. (2) To design and standardize the management of problems and situations in which the community is affected by public transport. (3) To construct a public transport application prototype for local communities of Thailand. The research method was based on the Software Development Life Cycle (SDLC) principle by selecting the V-Model quality assurance method. The V-Model components consist of 7 key phases: the 1 st phase is the define requirements phase, the 2nd phase is the system architecture phase, the 3rd is the detailed design phase, the 4th is the development phase, the 5th phase is the build and test phase, the 6th phase is the system integration and test phase, and the last phase is the deployment and verification phase. Population and sampling were scoped from the public transport service provider in Phayao Province, Thailand. The prototype was constructed with an Android Mobile Application. The results of the study showed that the developed application prototypes showed a high level of satisfaction (total means is equal to 3.95, S.D. is equal to 0.73) with the design and implementation of the prototype. For the future, the researcher will bring the application to the test and deployment.

\section{Conflict of Interest}

The authors declare no conflict of interest. 


\section{Acknowledgements}

This research is supported by two institutions. It consists of the University of Phayao, and the Kalasin Technical College. The authors would like to thank the advisor, lecturers, students, technicians, and all respondents for their entire support. This research was funded by the project of the Unit of Excellence in Applied Informatics for Modernization (FF64-UoE004) from the University of Phayao.

\section{References}

[1]. Calimag, J. N., Mugel, P. A., Conde, R. S., \& Aquino, L. B. (2014). Ubquitous learning environment using android mobile application. International Journal of Research in Engineering \& Technology, 2(2), 119-128.

[2]. Forsberg, K., \& Mooz, H. (1991). The relationship of system engineering to the project cycle. INCOSE International Symposium, 1(1), 57-65.

[3]. Liang, Z., \& ZHANG, W. (2009). Research and Design of Interface Based on Android Technology [J]. Computer Knowledge and Technology, 29, 041.

[4]. Nuankaew, P. (2020). Clustering of Mindset towards Self-Regulated Learning of Undergraduate Students at the University of Phayao. Advances in Science, Technology and Engineering Systems, 5(4), 676-685. https://doi.org/10.25046/aj050481

[5]. Nuankaew, P., Nuankaew, W., Teeraputon, D., Bussaman, S., \& Rattarom, S. (2020). Information Technology Educational Programs Situation in Disruptive Technology Era: Learning Strategies for Lifelong Learning. International Journal of Advanced Science and Technology, 29(05), 4960-4984.

[6]. Phanniphong, K., Nuankaew, P., Teeraputon, D., Nuankaew, W., Tanasirathum, P., \& Bussaman, S. (2018). The Distinction Learning Style in Learning Outcomes of the Secondary School Learner. 2018 3rd Technology Innovation Management and Engineering Science International Conference (TIMESICON), 1-5. https://doi.org/10.1109/TIMES-iCON.2018.8621778

[7]. Ruparelia, N. B. (2010). Software development lifecycle models. ACM SIGSOFT Software Engineering Notes, 35(3), 8-13. https://doi.org/10.1145/1764810.1764814 